\title{
Separate pulmonary venous anastomoses using a left atrial appendage in a left single lung transplantation
}

\author{
Toyofumi F. Chen-Yoshikawa, MD, Yasufumi Goda, MD, Li Dong, MD, and Hiroshi Date, MD, \\ Kyoto, Japan
}

\footnotetext{
From the Department of Thoracic Surgery and Anesthesiology, Kyoto University Graduate School of Medicine, Kyoto, Japan.

Disclosures: Authors have nothing to disclose with regard to commercial support.

Received for publication Dec 13, 2015; revisions received Jan 8, 2016; accepted for publication Jan 23, 2016; available ahead of print March 8, 2016.

Address for reprints: Hiroshi Date, MD, Department of Thoracic Surgery, Kyoto University Graduate School of Medicine, 54 Shogoin Kawahara-cho, Sakyo-ku, Kyoto 606-8507, Japan (E-mail: hdate@kuhp.kyoto-u.ac.jp). J Thorac Cardiovasc Surg 2016;152:e11-2

$0022-5223 / \$ 36.00$

Copyright (c) 2016 by The American Association for Thoracic Surgery

http://dx.doi.org/10.1016/j.jtcvs.2016.01.046
}

In lung transplantation, pulmonary venous anastomosis is sometimes technically challenging for several reasons, including inadequate cuff of recipient left atrial tissue, difficult exposure of the native left pulmonary venoatrial connection, and the inability to reposition the clamp more proximally. $^{1-3}$ We report a successful left single lung transplantation in which pulmonary venous anastomoses were performed separately, using the left atrial appendage for pulmonary venous drainage.

\section{CASE REPORT}

A 53-year-old man with idiopathic interstitial pneumonia was listed for lung transplantation. While on the waiting list, he developed recurrent right pneumothoraces, which required multiple surgical interventions, including muscle prombage. Lung perfusion scintigraphy revealed a the right-to-left ratio of 99:1.

One year later, single lung transplantation was scheduled. A left pneumonectomy was performed through a left thoracotomy without cardiopulmonary bypass. An anatomic variation of the common trunk of the left pulmonary vein was discovered. Bronchial anastomosis was performed without difficulty, but the patient's common trunk of the left pulmonary vein was too small to allow for direct anastomosis to the atrial cuff of the donor graft. Furthermore, shortly after tentative clamping of the patient's left atrium, cardiac arrest occurred, necessitating manual cardiac massage and bolus injection of catecholamine.

After this intensive treatment, the patient was eventually stabilized, but we found it difficult to enlarge his left atrial cuff by reclamping the left atrium more proximally. We then decided to anastomose the donor's superior and inferior pulmonary veins separately. The donor's inferior pulmonary vein was anastomosed to the common trunk of the patient's left pulmonary vein, and the donor's superior pulmonary vein was then anastomosed to the patient's left atrial appendage. Both venous anastomoses were performed successfully without cardiopulmonary bypass. Finally, anastomosis of the pulmonary artery was performed as

\section{DISCUSSION}

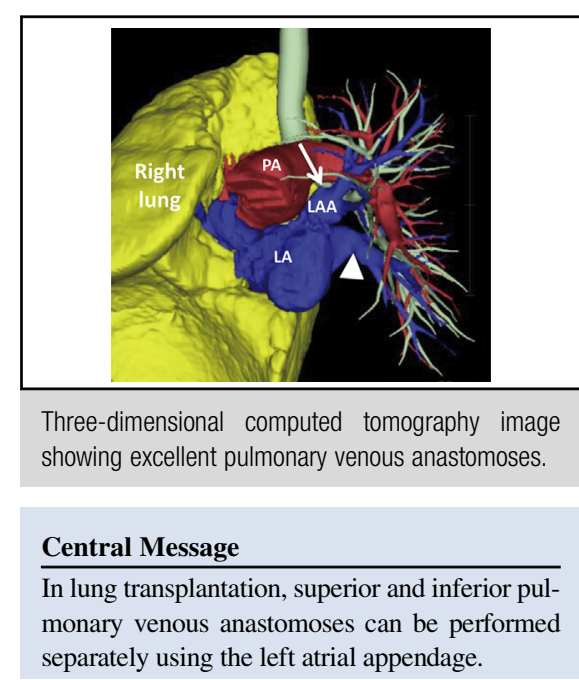

See Editorial Commentary page e13.

usual. The patient's postoperative course was uneventful. He was completely weaned from the respirator on day 3, and discharged from the hospital on day 26.

Currently, 8 months after lung transplantation, the patient is doing well without oxygen supplementation. Postoperative computed tomography revealed excellent pulmonary venous anastomoses (Figures 1 and 2).

In lung transplantation, it is common to use the atrial cuffs of the donor and the recipient to perform the pulmonary venous anastomosis, but the surgeon occasionally finds this difficult for several reasons. ${ }^{1-3}$ In our patient, the relatively small orifice of the common trunk of his left pulmonary vein, and the hemodynamic insufficiency at the time of clamping of his left atrium, made us abandon this common practice.

When exposure of the native left pulmonary venoatrial connection may be problematic, pulmonary venous drainage into the left atrial appendage is an alternative option to facilitate transplantation. ${ }^{2}$ In our patient, the orifice of the common trunk of the left pulmonary vein was relatively small, but sufficiently large to allow an anastomosis to the donor's inferior pulmonary vein with an adequate diameter. The donor's superior pulmonary vein was then anastomosed to the patient's left atrial appendage. In this way, separate superior and inferior pulmonary venous anastomoses were performed successfully with sufficient anastomotic diameters. Doing a single 


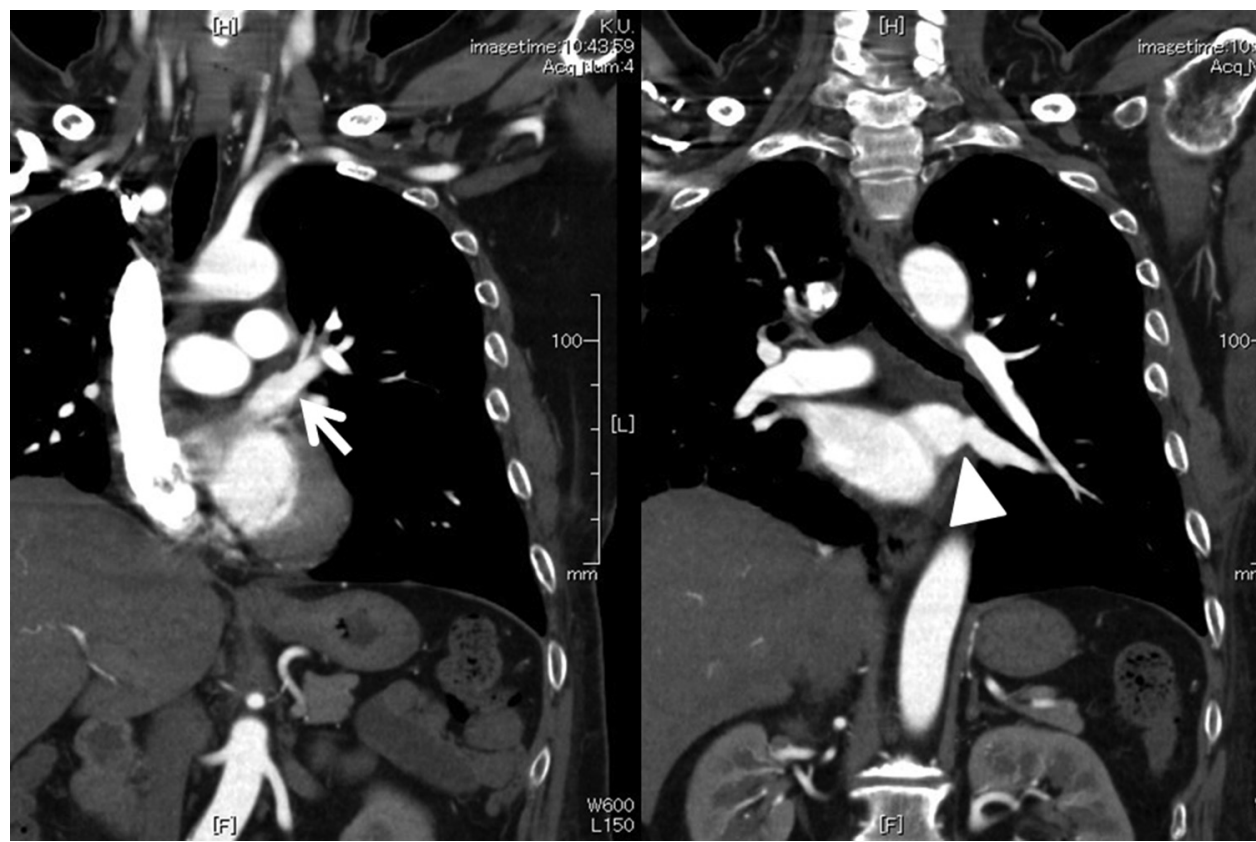

FIGURE 1. Postoperative chest computed tomography image showing excellent pulmonary venous anastomoses. Both anastomoses are widely open. In the left image, the arrow indicates the anastomosis of the donor's superior pulmonary vein to the recipient's left atrial appendage. In the right image, the arrowhead indicates the anastomosis of the donor's inferior pulmonary vein to the common trunk of the recipient's left pulmonary vein.

anastomosis (instead of 2 anastomoses on both veins) is easier and quicker, and minimizes the risks of stenosis and thus of thrombosis. ${ }^{4}$ However, pulmonary venous anastomosis is occasionally technically challenging, as in the present case, and in such cases this surgical technique might be a useful option for thoracic surgeons. This technique could be used in other scenarios, such as difficulty in vein exposure owing to cardiac enlargement. Although the left atrial appendage could handle

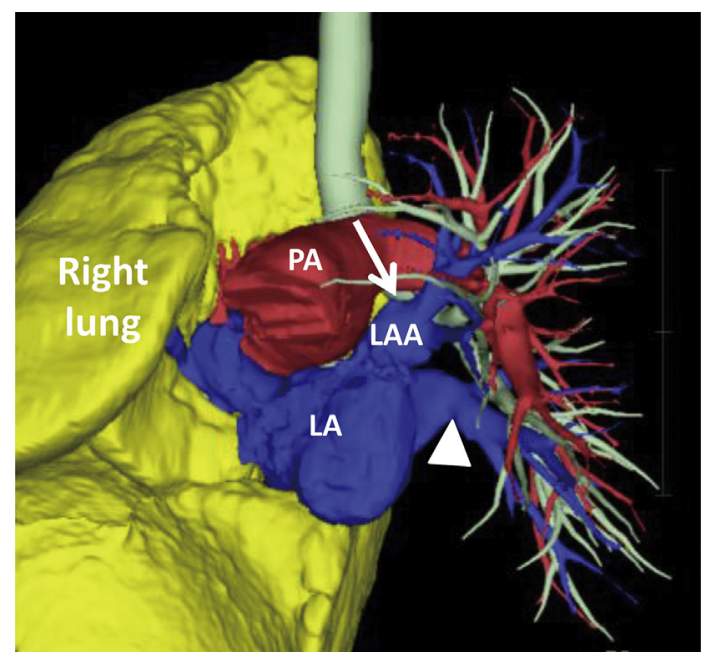

FIGURE 2. Postoperative 3-dimensional computed tomography image showing excellent pulmonary venous anastomoses. The arrow indicates the anastomosis of the donor's superior pulmonary vein to the recipient's left atrial appendage; the arrowhead indicates the anastomosis of the donor's inferior pulmonary vein to the common trunk of the recipient's left pulmonary vein. $P A$, Pulmonary artery; $L A$, left atrium; $L A A$, left atrial appendage. full drainage of all left lung venous return, avoiding the need to expose the veins at all, ${ }^{2}$ it should be kept in mind that using the atrial cuffs of the donor and the recipient for pulmonary venous anastomosis minimizes the risks of stenosis and thrombosis.

This is the first reported case in which the superior and inferior pulmonary venous anastomoses were performed separately, using the left atrial appendage for pulmonary venous drainage, in lung transplantation. The potential dangers of separating the pulmonary veins are the risks of rotational kink in the new connections and positional stenosis from leaving an upper pulmonary vein too long. Nonetheless, this surgical technique can be useful for technically challenging pulmonary venous anastomosis in lung transplantation.

We thank Drs Kenji Minakata and Kazuhiro Yamazaki for the intraoperative cardiovascular management of the patient, and Dr Toshiyuki Mizota for the intraoperative anesthetic management of the patient.

\section{References}

1. Marom EM, Herndon JE, Kim YH, McAdams HP. Variations in pulmonary venous drainage to the left atrium: implications for radiofrequency ablation. Radiology. 2004:230:824-9.

2. Massad MG, Sirois C, Tripathy S, Jaffe HA, Snow N, Geha AS. Pulmonary venous drainage into the left atrial appendage facilitates transplantation of the left lung with difficult exposure. Ann Thorac Surg. 2001;71:1046-7.

3. Bhama JK, Bansal A, Shigemura N, Toyoda Y. Reconstruction technique for a short recipient left atrial cuff during lung transplantation. Eur J Cardiothorac Surg. 2014;45:1106-7.

4. Robert JH, Murith N, de Perrot M, Bednarkiewicz M, Licker MJ, Spiliopoulos A. Lung transplantation: how to perform the venous anastomosis when clamping is too distal. Ann Thorac Surg. 2000;70:2164-5. 